2013

\title{
The Effectiveness of Prophylactic Ankle Braces in Reducing the Incidence of Acute Ankle Injuries in Adolescent Athletes: A Critically Appraised Topic
}

\author{
Kelley E. Farwell \\ Old Dominion University \\ Cameron J. Powden \\ Old Dominion University \\ Meaghan R. Powell \\ Old Dominion University \\ Cailee W.McCarty \\ Matthew C. Hoch \\ Old Dominion University, mhoch@odu.edu
}

Follow this and additional works at: https://digitalcommons.odu.edu/hms_fac_pubs

Part of the Rehabilitation and Therapy Commons, and the Sports Sciences Commons

\section{Repository Citation}

Farwell, Kelley E.; Powden, Cameron J.; Powell, Meaghan R.; McCarty, Cailee W.; and Hoch, Matthew C., "The Effectiveness of Prophylactic Ankle Braces in Reducing the Incidence of Acute Ankle Injuries in Adolescent Athletes: A Critically Appraised Topic" (2013). Human Movement Sciences Faculty Publications. 62.

https://digitalcommons.odu.edu/hms_fac_pubs/62

\section{Original Publication Citation}

Farwell, K. E., Powden, C. J., Powell, M. R., McCarty, L. W., \& Hoch, M. C. (2013). The effectiveness of prophylactic ankle braces in reducing the incidence of acute ankle injuries in adolescent athletes: A critically appraised topic. Journal of Sport Rehabilitation, 22(2), 137-142. doi: $10.1123 /$ jsr.22.2.137 


\title{
The Effectiveness of Prophylactic Ankle Braces in Reducing the Incidence of Acute Ankle Injuries in Adolescent Athletes: A Critically Appraised Topic
}

\author{
Kelley E. Farwell, Cameron J. Powden, Meaghan R. Powell, \\ Cailee W. McCarty, and Matthew C. Hoch
}

\begin{abstract}
Clinical Scenario: Ankle injuries constitute a large number of injuries sustained by adolescent athletes participating in high school athletics. Prophylactic ankle bracing may be an effective and efficient method to reduce the incidence of ankle injuries in adolescent athletes in the secondary-school setting. Clinical Question: Do prophylactic ankle braces reduce the incidence of acute ankle injuries in adolescent athletes? Summary of Key Findings: Two of the three included studies reported that prophylactic ankle braces reduced the incidence of ankle injuries compared with no ankle bracing. Clinical Bottom Line: There is moderate evidence to support the use of prophylactic ankle braces in adolescent athletes, particularly those who participate in football and basketball, to reduce the incidence of acute ankle injuries. Strength of Recommendation: Grade B evidence exists that prophylactic ankle braces reduce the incidence of acute ankle injuries in adolescent athletes.
\end{abstract}

Keywords: ankle sprain, injury prevention, ankle support

\section{Clinical Scenario}

There is a high incidence of ankle injuries in adolescent athletes, with ankle sprains accounting for up to $40 \%$ of all reported injuries. ${ }^{1}$ The frequency of ankle injuries places a monetary burden on the health care system and also stresses the need for clinicians to seek out prophylactic mediums to reduce ankle-injury incidence. ${ }^{1}$ The application of ankle taping or ankle bracing is a frequently used strategy to prevent ankle injuries in adolescent athletes. However, taping can be costly and time consuming for athletic trainers, particularly in the secondary-school setting. Therefore, prophylactic ankle bracing may be an effective and efficient method to reduce the incidence of ankle injuries in adolescent athletes in the secondaryschool setting.

\section{Focused Clinical Question}

Do prophylactic ankle braces reduce the incidence of acute ankle injuries in adolescent athletes?

Farwell, Powden, and Powell are with the Dept of Human Movement Science, and Hoch, the School of Physical Therapy and Athletic Training, Old Dominion University, Norfolk, VA. McCarty is with the Arizona School of Health Sciences, A.T. Still University, Mesa, AZ.

\section{Summary of Search, "Best Evidence" Appraised, and Key Findings}

- The literature was searched for studies of level 2 evidence or higher that investigated the effect of prophylactic ankle braces on acute ankle-injury incidence in adolescent athletes.

- The literature search returned 5 possible studies related to the clinical question; 3 studies met the inclusion criteria and were included.

- Two randomized control trials (RCTs) and 1 prospective cohort study were included.

- The 2 RCT studies reported that high school athletes who wore prophylactic ankle braces demonstrated a reduction in acute ankle-injury rates compared with those who did not wear a brace.

- Both RCT studies reported that the incidence of ankle injury was reduced but the severity of ankle injuries was not.

- The prospective cohort study did not find a reduction in acute ankle injury in adolescent male and female volleyball athletes who wore ankle braces compared with those who did not.

\section{Clinical Bottom Line}

There is moderate evidence to support the use of prophylactic ankle braces in adolescent athletes, particularly 
those who participate in football and basketball, to reduce the incidence of acute ankle injuries. ${ }^{2,3}$ There is a need for additional studies to determine the strength of evidence to support the use of ankle braces in adolescent volleyball athletes. ${ }^{3}$

Strength of Recommendation: Grade B evidence exists that prophylactic ankle braces reduce the incidence of acute ankle injuries in adolescent athletes.

\section{Search Strategy}

\section{Terms Used to Guide Search Strategy}

- Patient/Client group: high school athletes or adolescent athletes

- Intervention/Assessment: lace-up ankle braces or prophylactic ankle braces

- Comparison: control group (no ankle brace)

- Outcome: occurrence of ankle sprains

\section{Sources of Evidence Searched}

- MEDLINE

- EBSCOHost

- CINAHL

- Cochrane Database

- SPORTDiscus

- Additional resources obtained via review of reference lists and hand search

\section{Inclusion and Exclusion Criteria}

\section{Inclusion Criteria}

- Studies that investigated acute ankle injuries in high school athletes

- Studies that used a form of prophylactic ankle brace for the duration of at least 1 high school sports season

- Level 2 evidence or higher

- Limited to English language

- Limited to the past 10 years (2003-2012)

\section{Exclusion Criteria}

- Participants who were not eligible to compete at the high school level
- Studies that did not include prophylactic ankle-brace interventions

- Studies that compared ankle braces with other prophylactic methods (eg, tape, rehabilitation, modalities)

\section{Results of Search}

Three relevant studies ${ }^{2-4}$ were located and categorized as described in Table 1 (based on Levels of Evidence, Oxford Centre for Evidence-Based Medicine, 2009).

\section{Best Evidence}

The studies in Table 2 were identified as the best evidence and selected for inclusion in this critically appraised topic (CAT). These studies were selected because they were considered level 2 evidence or higher, investigated the use of prophylactic ankle bracing among adolescent athletes, and described the effect of this intervention on incidence of acute ankle injuries.

\section{Implications for Practice, Education, and Future Research}

Two of the three studies found a significant reduction in acute ankle-injury incidence with the use of prophylactic ankle braces during a high school sport season. ${ }^{2,3}$ These results were consistent among adolescent athletes with and without a previous history of ankle injury. ${ }^{2,3}$ It is also important to note that none of the 3 studies demonstrated an increased incidence of acute ankle sprains in the ankle-brace group compared with the control group. ${ }^{2-4}$ Cumulatively, these findings indicate that the use of prophylactic ankle braces across an athletic season is effective in reducing acute ankle injuries in adolescent athletes.

Based on the included studies, adolescent football and basketball athletes may benefit more than volleyball athletes from using prophylactic ankle braces to reduce acute ankle injuries. ${ }^{2-4}$ While these findings may be the result of methodological differences across studies, such as study design or type of ankle brace used as the intervention, it may be due to the different demands of each sport on the athlete. Based on the nature of football and basketball, athletes have more frequent opportunities for direct physical contact with other players in comparison with volleyball athletes. Football (61.9\%) and basketball

Table 1 Summary of Study Designs of Articles Retrieved

\begin{tabular}{llll}
\hline Level of evidence & Study design & Number located & Reference \\
\hline $\mathrm{lb}$ & $\begin{array}{l}\text { Cluster randomized } \\
\text { controlled trial }\end{array}$ & 2 & McGuine et $\mathrm{al}^{2}$ \\
& Prospective cohort & 1 & McGuine et $\mathrm{al}^{3}$ \\
$\mathrm{2b}$ & & Frey et al ${ }^{4}$ \\
\hline
\end{tabular}




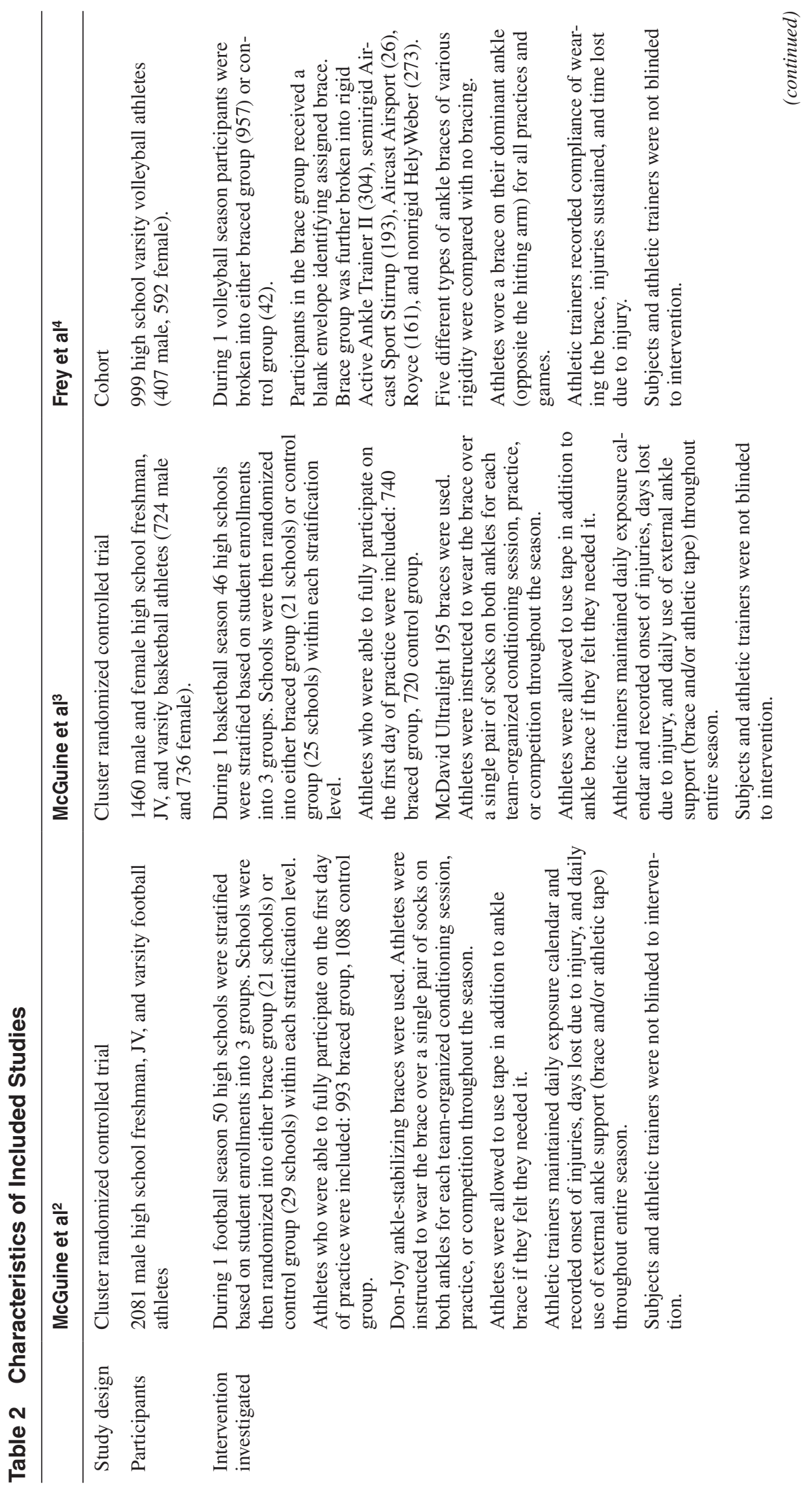




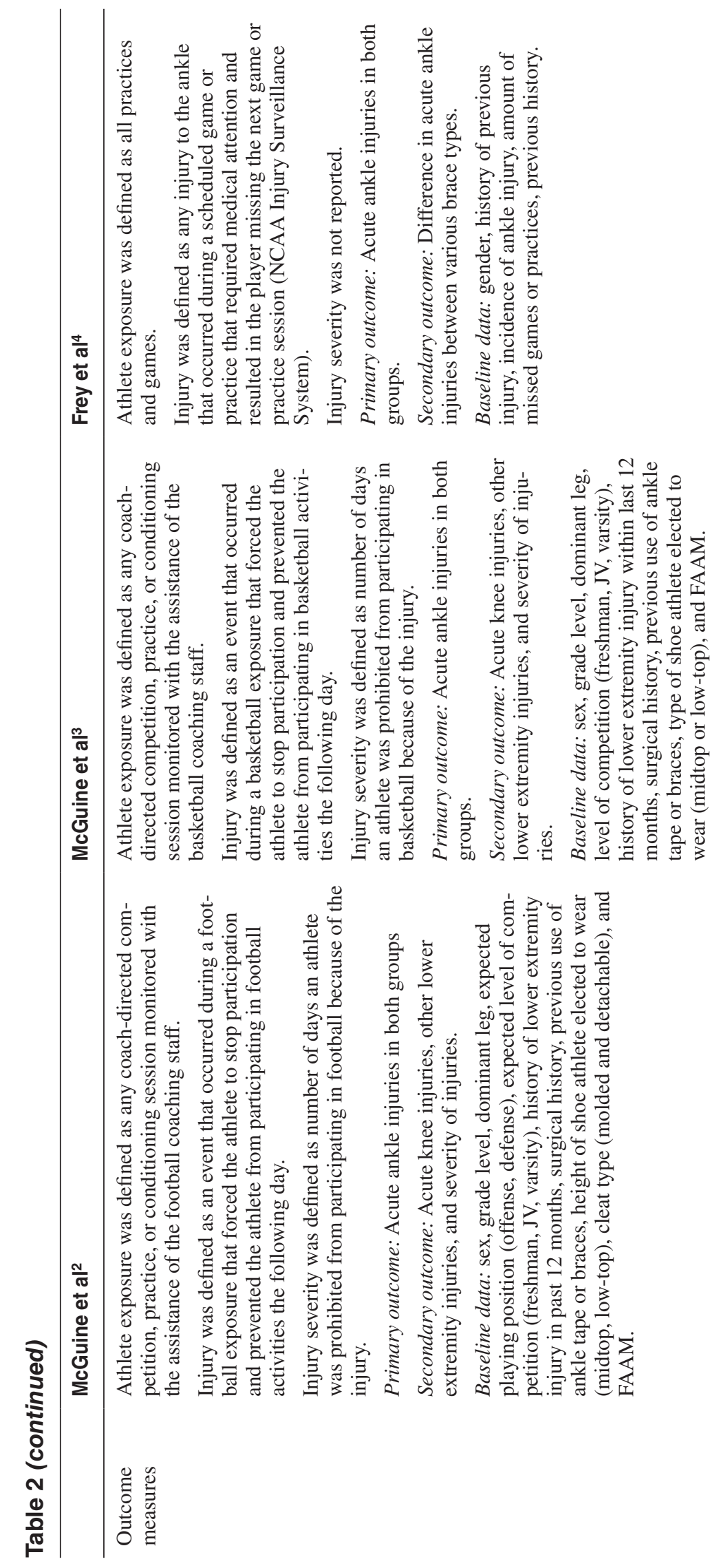



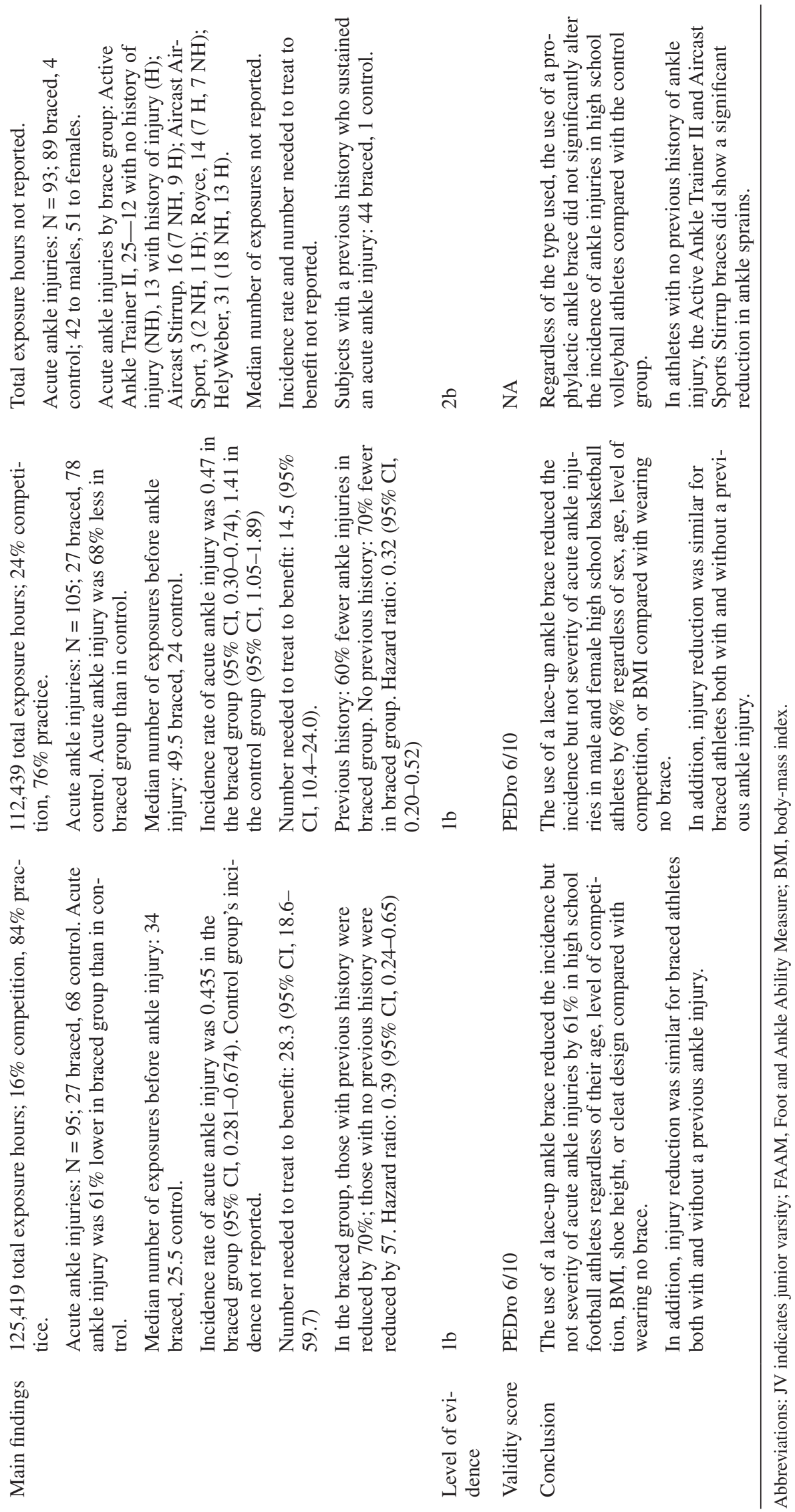
(40.5\%) athletes have a larger percentage of total injuries due to player-to-player contact than do volleyball athletes $(23.1 \%) .{ }^{5}$ Therefore, the different demands in each sport could be a reason why football and basketball athletes may benefit more from ankle braces than volleyball athletes would.

Two of the included studies ${ }^{2,3}$ performed an analysis of numbers needed to treat to benefit (NNTB) to identify how many athletes would need to use a brace to prevent an ankle injury. These studies determined that approximately 29 football athletes ${ }^{2}$ and 15 basketball athletes ${ }^{3}$ need to be braced during an entire season to prevent 1 ankle injury. Comparatively, previous research that implemented a balance-training program before and during a high school soccer and basketball season determined that 27 athletes needed to participate in the program to prevent a single ankle injury. ${ }^{6}$ Although the NNTB for balance training is similar to the numbers reported with the use of ankle bracing, factors such as time, compliance, and direct supervision should be considered in a secondary school setting. While it is beyond the scope of this CAT to determine which intervention is more effective, prophylactic ankle bracing may be more efficient for high school athletic trainers to use, as this intervention may not require the time and personnel necessary to implement a balance-training program.

Future research should explore the use of prophylactic ankle braces among a variety of different high school athletics, as the studies in this CAT only targeted football, basketball, and volleyball. Furthermore, identifying specific athletes who may benefit most from bracing would enhance the overall feasibility of this intervention. In addition, the studies included in this CAT only examined a single athletic season. Examining the effectiveness of ankle braces across multiple seasons may provide more robust evidence to complement the existing research in this area. This CAT should be reviewed in 2 years or when additional best evidence becomes available that may change the clinical bottom line for this clinical question.

\section{References}

1. Knowles SB, Marshall SW, Miller T, et al. Cost of injuries from a prospective cohort study of North Carolina high school athletes. Inj Prev. 2007;13(6):416-421.

2. McGuine TA, Hetzel S, Wilson J, Brooks A. The effect of lace-up ankle braces on injury rates in high school football players. Am J Sports Med. 2012;40(1):49-57.

3. McGuine TA, Brooks A, Hetzel S. The effect of lace-up ankle braces on injury rates in high school basketball players. Am J Sports Med. 2011;39(9):1840-1848.

4. Frey C, Feder KS, Sleight J. Prophylactic ankle brace use in high school volleyball players: a prospective study. Foot Ankle Int. 2010;31(4):296-300.

5. Kerr ZY, Collins CL, Fields SK, Comstock RD. Epidemiology of player-player contact injuries among US high school athletes, 2005-2009. Clin Pediatr. 2011;50(7):594603.

6. McGuine TA, Keene JS. The effect of a balance training program on the risk of ankle sprains in high school athletes. Am J Sports Med. 2006;34(7):1103-1111. 